\title{
A IMPORTÂNCIA DO SISTEMA AQÜÍFERO SERRA GERAL PARA A CULTURA DA SOJA NO ESTADO DO PARANÁ
}

\section{THE IMPORTANCE OF THE SERRA GERAL AQUIFER SISTEM TO THE SOYBEAN CULTURE IN PARANÁ STATE (BRAZIL)}

\author{
Ernani Francisco da Rosa Filho ${ }^{1}$, Eduardo Chemas Hindi ${ }^{1}$, \\ Luiz Eduardo Mantovani ${ }^{1}$ e André Virmond Lima Bittencourt ${ }^{1,2}$
}

Recebido em: 20/06/2006; aceito em: 17/09/2006

\begin{abstract}
RESUMO A falta ou a insuficiência de chuvas nos períodos de floração e crescimento da soja são alguns dos principais fatores que causam a perda ou redução da safra nos três estados do sul do Brasil. Apenas em território paranaense, a área plantada de soja é de aproximadamente 3.650 .000 hectares, ou $36.500 \mathrm{~km}^{2}$, o que equivale a aproximadamente $18,3 \%$ de sua área. Neste período crítico é necessária uma quantidade de no mínimo $30 \mathrm{~mm} / \mathrm{mês}$ de chuvas, sem a qual ocorre a perda da safra, como ocorreu em fevereiro de 2005. A necessidade de água para a soja se desenvolver é de $1 \mathrm{~L} \cdot \mathrm{dia}^{-1} \cdot \mathrm{m}^{-2}$. Excetuando-se a região da bacia hidrografia do rio Iguaçu, onde a média é de $5 \mathrm{~m}^{3} . \mathrm{h}^{-1}$, a produtividade dos poços perfurados no Sistema Aqüífero Serra Geral (SASG), varia de 21 a $35 \mathrm{~m}^{3} \cdot \mathrm{h}^{-1}$. Em aproximadamente $90 \%$ dos poços, as entradas de água se distribuem em profundidades inferiores a $170 \mathrm{~m}$. Para vazões de poços entre $25 \mathrm{~m}^{3} \cdot \mathrm{h}^{-1} \mathrm{e} 100 \mathrm{~m}^{3} \cdot \mathrm{h}^{-1}$, a capacidade para irrigar uma plantação de soja abrange uma área que varia de $600.000 \mathrm{~m}^{2}$ a $2.400 .000 \mathrm{~m}^{2}$, respectivamente. As águas do SASG apresentam Risco de Sódio variando de baixo a médio e Risco de Salinidade predominantemente baixo.
\end{abstract}

Palavras-chave: Sistema Aqüífero Serra Geral, irrigação, água subterrânea, soja, irrigação.

\begin{abstract}
The lack or insufficient amount of rain fall during the blooming and growing periods of soybeans are one of the major factors that cause either complete loss or large reductions of harvest areas in the southern region of Brazil. Within the Paraná State the soybeans agriculture covers an area of approximately 3,650,000 hectares $\left(36,500 \mathrm{~km}^{2}\right)$, which is equivalent to nearly $18.3 \%$ of the State's total geographical surface. Hence, these areas need a minimum of $30 \mathrm{~mm}$ per month of rain fall in order to maintain the sustainable activity in the long term, taking for instance the extensive loss of soybeans crop that took place in February 2005 due to the lack of rain. In order to flourish, soybeans needs $1 \mathrm{~L}^{-d a y}{ }^{-1} \cdot \mathrm{m}^{-2}$. The yield of wells drilled into the Serra Geral Aquifer System (SASG) can vary from 21 a $35 \mathrm{~m}^{3} \cdot \mathrm{h}^{-1}$, with the exception of the ones drillled inside the Iguaçu river basin, that show average yield of $5 \mathrm{~m}^{3} \cdot \mathrm{h}^{-1}$. In almost $90 \%$ of the wells, water can be found within less than $170 \mathrm{~m}$ deep. In wells which discharges vary from $25 \mathrm{~m}^{3} \cdot \mathrm{h}^{-1}$ to $100 \mathrm{~m}^{3} \cdot \mathrm{h}^{-1}$, their capacity to irrigate an soybean crop, can cover an area of $600,000 \mathrm{~m}^{2}$ and $2,400,000 \mathrm{~m}^{2}$, respectively. SASG waters presenta low to medium sodium risk and also a predominately low risk of salinity.
\end{abstract}

Keywords: Serra Geral Aquifer System, irrigation, groundwater, soybeans.

\section{INTRODUÇÃO}

Apesar da Região Sul do Brasil ser úmida no seu conjunto, poucas são as suas áreas onde a precipitação é realmente suficiente, durante todos os meses do ano, a ponto de não causar prejuízos nas safras de grãos por falta de chuvas. A falta ou a insuficiência de chuvas, mesmo em curtos períodos de tempo, tal como aconteceu nos Estados do Rio Grande do Sul, Santa Catarina e Paraná, causaram, no segundo mês do ano de 2005, um prejuízo na produção de grãos, em especial da soja e do milho, cerca de doze bilhões de reais (aproximadamente seis bilhões de dólares americanos). Além destes destacam-se, os prejuízos indiretos, a exemplo do comércio e do transporte, que não foram computados no montante mencionado.

Diante deste quadro, tornou-se imprudente qualquer afirmação que denote a inexistência de períodos de seca na região sul do Brasil. A falta de irrigação nas culturas de soja e de milho, mesmo em grandes propriedades, está relacionada à ausência de planejamento adequado às condições climáticas. A água, nesses casos, representa um dos insumos mais importantes para a plantação e colheita dessas culturas, especialmente nas regiões onde o solo resulta da ação intempérica em rochas efusivas da Formação Serra Geral.

A precipitação insuficiente e a não utilização das águas subterrâneas como fonte para procedimentos de irrigação já resultou na redução do Produto Interno Brasileiro (PIB) durante os anos que períodos de estiagem aconteceram de forma mais intensa. Diante de um quadro de mudanças climáticas que afeta a distribuição de chuvas, ora abundantes, ora insuficientes, tornase de fundamental importância, a inclusão de procedimentos emergenciais de irrigação, no planejamento da atividade agrícola.

\footnotetext{
${ }^{1}$ Laboratório de Pesquisas Hidrogeológicas da UFPR (ernani@ufpr.br); (hindi@ufpr.br); (lem@ufpr.br); (andre@ufpr.br)

${ }^{2}$ Curso de pós-graduação em Gestão Ambiental do UNICENP (avlb@unicenp.br)
} 
A soja, seguida pelo milho, foram os produtos agrícolas que mais sofreram com a longa estiagem ocorrida na Região Sul. Houve uma quebra de $54 \%$ relativa à soja, e de $39 \%$ na produção de milho, referentes à primeira e segunda safra. Apenas no Estado do Rio Grande do Sul, a estiagem de 2005 causou uma redução de $70 \%$ na produção e de $98 \%$ na exportação de grãos soja.No Estado do Paraná, as regiões mais prejudicadas localizam-se no oeste e sudoeste do estado, concentrando-se nos municípios produtores do núcleo de Campo Mourão, de Londrina e de Cornélio Procópio.

As regiões paranaenses mencionadas situam-se sobre o Sistema Aqüífero Serra Geral (SASG). Nessas regiões, as vazões médias dos poços que seccionam as estruturas aquíferas do SASG, oscilam entre 5 e $35 \mathrm{~m}^{3} \cdot \mathrm{h}^{-1}$, sendo que existem poços cuja produção atinge valores superiores a $100 \mathrm{~m}^{3} \cdot \mathrm{h}^{-1}$. A qualidade da água deste aqüífero é adequada para a irrigação das culturas mencionadas. Esta seria, portanto, a principal alternativa de fonte de água doce da região para minimizar os efeitos da seca e evitar os prejuízos acima descritos.

\section{OBJETIVO}

O objetivo deste trabalho é mostrar que as águas armazenadas no SASG podem ser usadas para a irrigação de plantações de soja e de milho, assim como de outras culturas, em períodos críticos de estiagens durante os meses de floração e crescimento dessas culturas.

\section{BASE DE DADOS}

\section{Precipitação}

Os dados de longo período, monitorados pela SUDERHSA (Superintendência dos Recursos Hídricos e Saneamento Ambiental), mostram que entre os meses de outubro e fevereiro ocorrem, em média, as precipitações mais elevadas. No entanto, no mês de fevereiro/2005, o total de precipitação em algumas regiões do Paraná foi anômalo em relação à média, chegando a atingir valores típicos de um mês seco como agosto. O desvio entre a precipitação acumulada mensal em fevereiro/2005 e a média histórica (IAPAR, 2007), bem como as precipitações totais no mês de fevereiro (período: 1997-2005), registradas em algumas estações pluviométricas do interior do Paraná, estão apresentadas na tabela 1 e na figura 1 .

\section{Período crítico}

Considera-se como período crítico, ao tempo entre a floração e a formação de grãos. Caso a ocorrência de chuvas fique abaixo de 30 mm.mês ${ }^{-1}$, durante o período crítico, haverá uma influência direta e negativa na safra grãos.

A necessidade de água para a soja, no período da brotação e crescimento dos grãos, corresponde a $1 \mathrm{~L}^{\mathrm{d}} \mathrm{dia}^{-1} \cdot \mathrm{m}^{-2}$.

A área plantada de soja no Paraná é de aproximadamente 3.650 .000 ha, ou $36.500 \mathrm{~km}^{2}$, o que equivale a $18,3 \%$ da superfície do Estado. A estiagem ocorrida em fevereiro/2005 (Figura 1), que poderá se repetir neste mesmo mês nos anos subseqüentes, coincidiu com o período crítico da cultura da soja, causando a quebra da safra e afetando economia do Estado.

Por conta da extensão das áreas plantadas e do fato de se tratar de uma ação para atender ao requerimento mínimo das culturas após déficits hídricos extemporâneos ou de veranicos durante o período das chuvas, a irrigação por aspersão parece ser o mais adequado dentre os métodos convencionais de irrigação.

\section{ORIGEM DA ÁGUA A SER USADA NA IRRIGAÇÃO \\ Contexto geológico}

A Formação Serra Geral é constituída, preponderantemente, por basaltos toleíticos, com textura microcristalina e estruturas que refletem sua gênese através de sucessivos e intermitentes derrames de lava (LEINZ, 1949). De acordo com Ruëgg (1969) e Piccirillo et al. (1988), a composição mineralógica essencial dessas rochas constitui-se predominantemente de plagioclásio (andesina), seguido de augita e pigeonita. Ainda conforme este autor as análises químicas revelam uma predominância de óxidos de silício, seguidos pelos óxidos de alumínio, de ferro, de cálcio, de magnésio, de sódio, de titânio e de potássio.

Os derrames constituem unidades sobrepostas de extensão lateral e continuidade vertical. Conforme o movimento, resfriamento e conteúdo em gases da lava, a estrutura dos derrames pode ser caracterizada por uma zona basal, uma zona intermediária e uma zona de topo de derrame vesicular e/ou amigdaloidal. A espessura dessa seqüência de derrames alcança valores acima de $1.700 \mathrm{~m}$ nas regiões centrais da Bacia Sedimentar do Paraná como registrado no poço perfurado pelo PAULIPETRO em Cuiabá Paulista (SP). A localização da Formação Serra Geral na Bacia Geológica do Paraná está mostrada na figura 2 . 
Tabela 1- Precipitação total registrada no mês de fevereiro no período 1997-2005 (em mm)

Table 1- Accumulated precipitation recorded on February, from 1997-2005 (in mm)

\begin{tabular}{lccccccccc}
\hline $\begin{array}{c}\text { Nome da estação } \\
\text { pluviométrica }\end{array}$ & $\mathbf{1 9 9 7}$ & $\mathbf{1 9 9 8}$ & $\mathbf{1 9 9 9}$ & $\mathbf{2 0 0 0}$ & $\mathbf{2 0 0 1}$ & $\mathbf{2 0 0 2}$ & $\mathbf{2 0 0 3}$ & $\mathbf{2 0 0 4}$ & $\mathbf{2 0 0 5}$ \\
\hline Santo Antônioda Platina & 228,7 & 271,6 & 139,8 & 294,2 & 261,7 & 122,1 & 208,7 & 160,0 & 6,6 \\
Toledo & 155,9 & 352,2 & 145,1 & 331,7 & 176,0 & 126,4 & 235,3 & 45,1 & 29,5 \\
Londrina & 273,8 & 276,7 & 171,0 & 338,7 & 301,2 & 134,4 & 97,8 & 116,2 & 26,6 \\
Francisco Beltrão & 437,1 & 284,4 & 217,1 & 245,2 & 356,4 & 59,9 & 230,3 & 24,6 & 6,0 \\
\hline \multicolumn{1}{c}{ Média } & 273,9 & 242,9 & 168,2 & 302,4 & 273,8 & 110,7 & 193,0 & 86,5 & 17,2 \\
\hline
\end{tabular}

Dados fornecidos pela SUDERHSA (2005)

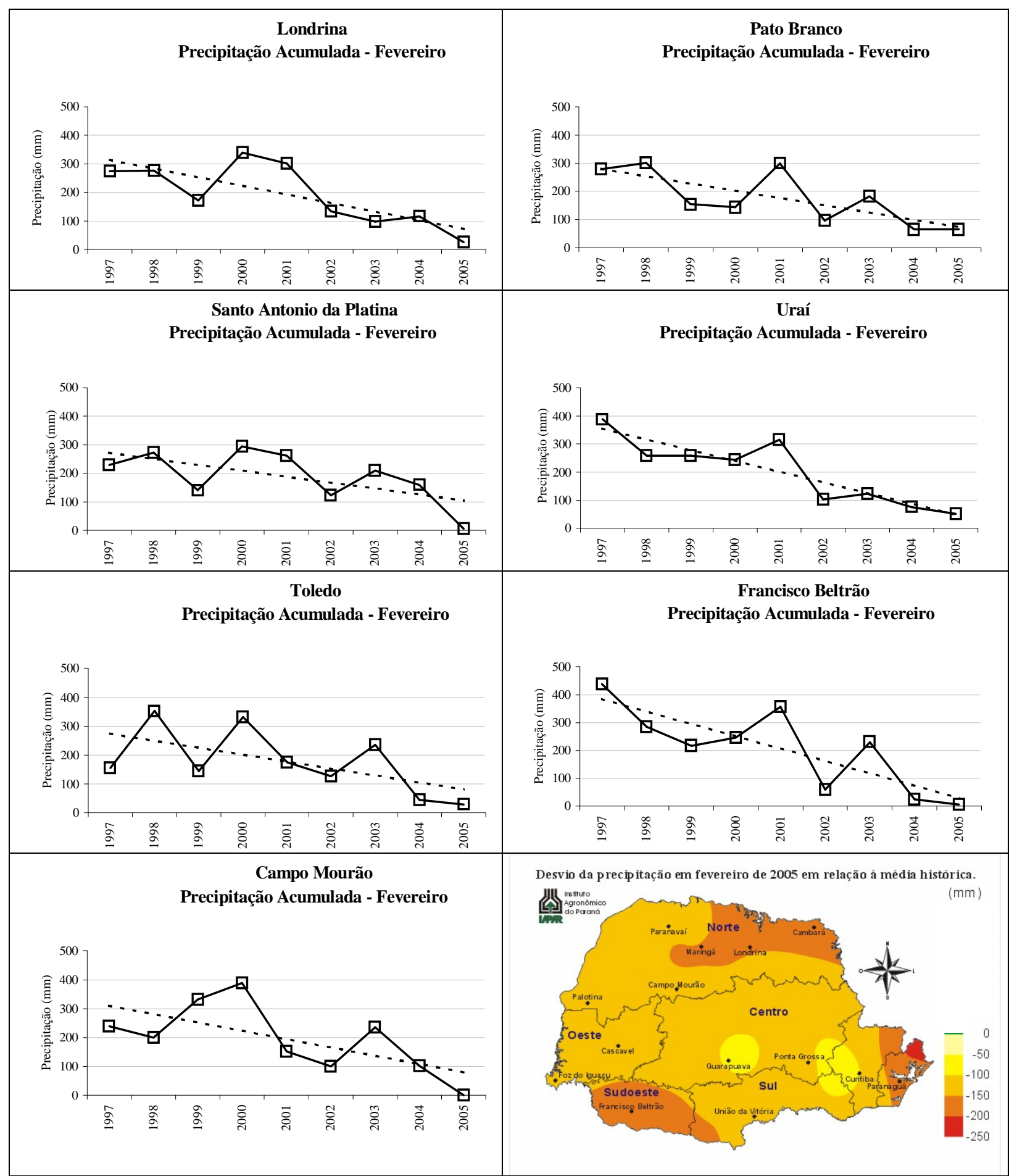

Figura 1- Variação da precipitação total do mês de fevereiro (período: 1997-2005) em várias estações pluviométricas do interior de Paraná (em mm)

Figure 1- Accumulated precipitation recorded on February (1997-2005) for various locations in Paraná State (in mm) 


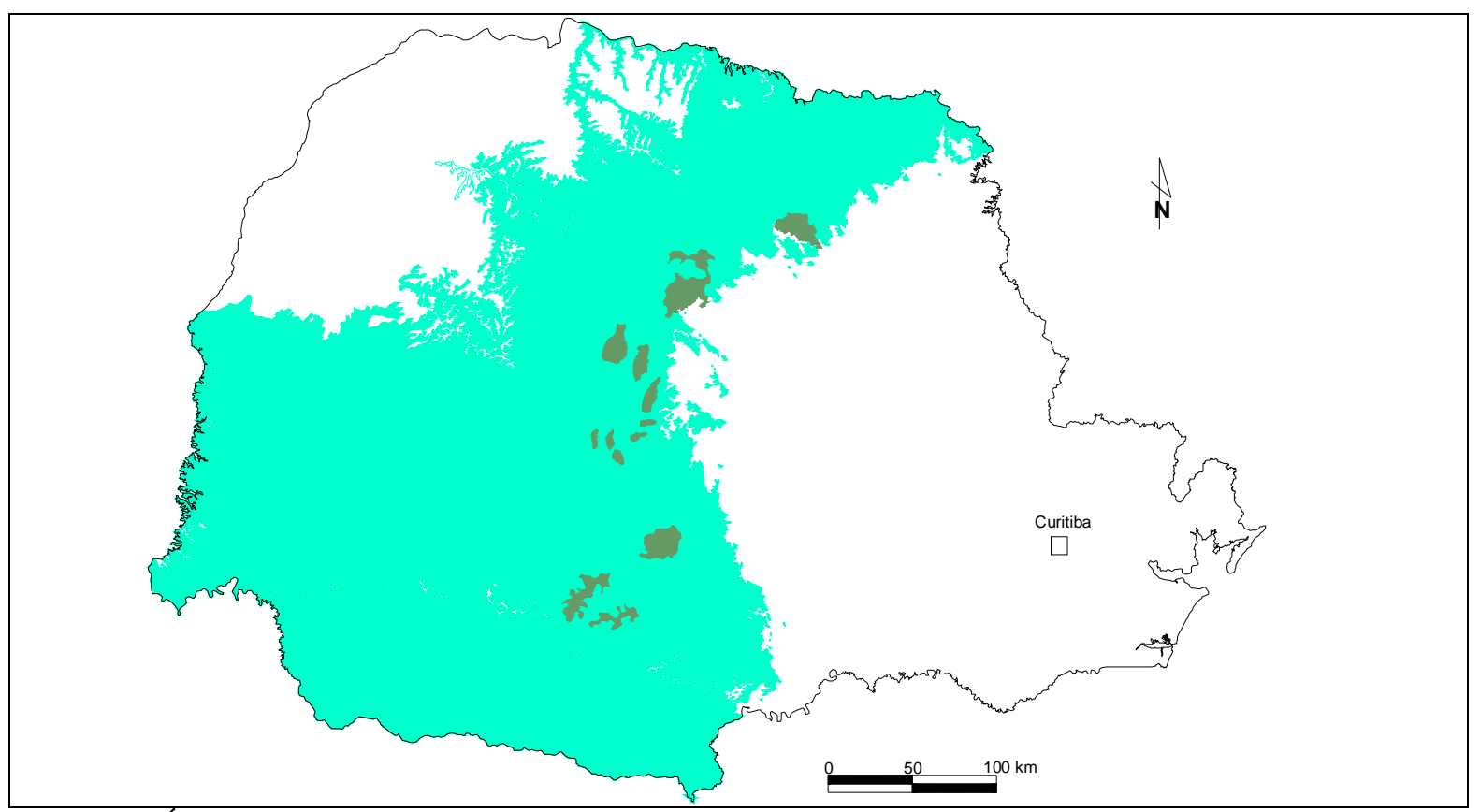

Figura 2- Área de ocorrência da Formação Serra Geral no Estado do Paraná (Modificado de MINEROPAR, 1989)

Figure 2- Serra Geral Formation location map in Paraná State, Brazil (Modifyed from MINEROPAR, 1989)

As principais direções dos lineamentos estruturais, onde as águas do SASG encontram-se armazenadas foram descritas por Rosa Filho et al. (1987). Essas estruturas, no norte e centro do Estado do Paraná, são consequiência do soerguimento do Arco de Ponta Grossa, cujos alinhamentos estruturais regionais foram estudado por Ferreira (1982), Vieira (1973), Soares (1981), Portela (2002) e Strugalle (2002).

\section{Contexto hidrogeológico}

O Sistema Aqüífero Serra Geral (SASG) devido às suas características litológicas não possui porosidade e permeabilidade primárias importantes para o armazenamento de volumes significativos de água. $\mathrm{O}$ armazenamento e a circulação da água ocorrem segundo as descontinuidades físicas da rocha (juntas, falhas geológicas e superfícies interderrames), constituindo-se em um meio heterogêneo e anisotrópico (REBOUÇAS, 1978).

A condutividade hidráulica é muito variável e de difícil avaliação em razão da complexidade das feições litológicas e estruturais através das quais a água circula.

Conforme estudos, enfocando as características químicos, realizados por Bittencourt (1978), Rosa Filho; Bittencourt; Salamuni (1987) e Celligoi (1994), verificou-se que a tipologia das águas armazenadas nas rochas basálticas é preferencialmente bicarbonatada cálcica, com baixos teores de sólidos totais dissolvidos (Figura 3).

Bittencourt (1978) e Rosa Filho; Bittencourt; Salamuni (1987), admitem que a presença de águas classificadas como bicarbonatadas sódicas sugere a mistura com as águas de aqüíferos subjacentes, a exemplo do Sistema Aqüífero Guarani (SAG) e de unidades paleozóicas. 


\section{Serra Geral}
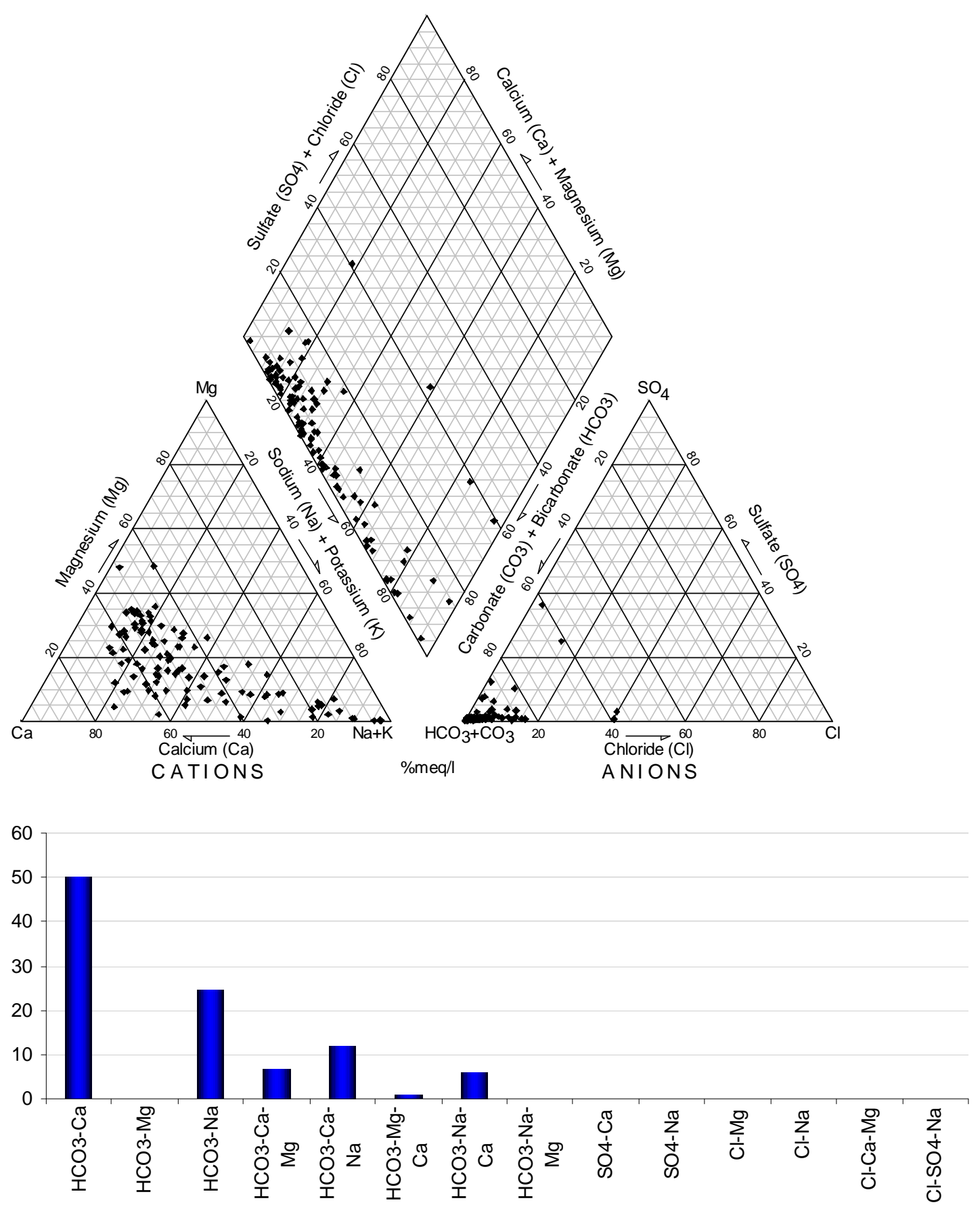

Figura 3- Diagrama de Piper e gráfico de barras representando, respectivamente, o conteúdo relativo de macroconstituintes iônicos e a frequiência (em \%) dos tipos de água do SASG, no Estado do Paraná (HINDI, 2007)

Figura 3- Piper diagram and column graph showing, respectively, the relative content of major components and the frequency (\%) of water types from the Serra Geral Aquifer System in Paraná State, Brazil (HINDI, 2007) 
A figura 3 foi elaborada com dados de amostras de águas coletadas em poços perfurados nas bacias hidrográficas do Iguaçu, Piquiri, Paraná III e Ivaí, apresentadas na figura 4.

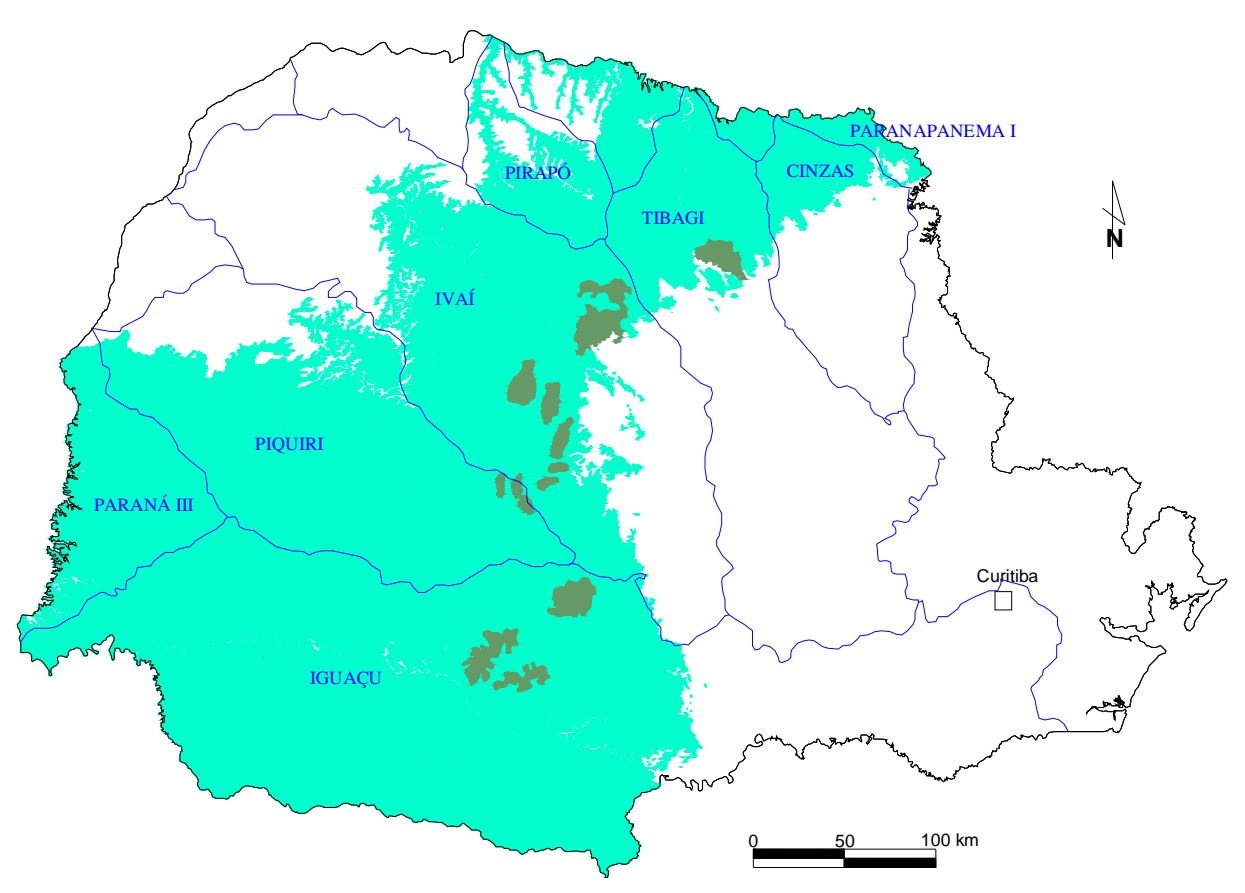

Figura 4- Localização das grandes bacias hidrográficas paranaenses. (SUDERHSA, 2006)

Figura 4- River basin location map in Paraná State, Brazil (SUDERHSA,2006)

Em termos quantitativos, Rosa Filho; Bittencourt; Salamuni (1987) estabeleceram que na área da bacia do rio Iguaçu sobre o Terceiro Planalto Paranaense, a vazão média dos poços é da ordem de $5 \mathrm{~m}^{3} \cdot \mathrm{h}^{-1}$., sendo que as entradas de água ocorrem até profundidades de $170 \mathrm{~m}$. Na bacia do rio Piquiri, a média das vazões gira em torno de $28 \mathrm{~m}^{3} \cdot \mathrm{h}^{-1}$, e as profundidades mais comuns de entradas de água ocorrem até os $90 \mathrm{~m}$. $\mathrm{Na}$ bacia do rio Paraná III, as vazões médias são da ordem de $35 \mathrm{~m}^{3} \cdot \mathrm{h}^{-1}$, com entradas de água distribuídas até $170 \mathrm{~m}$ de profundidade. $\mathrm{Na}$ região de abrangência da bacia do Ivaí, a média da produtividade dos poços é de $21 \mathrm{~m}^{3} \cdot \mathrm{h}^{-1}$, com entradas de água mais importantes situadas até $150 \mathrm{~m}$ de profundidade.

Mais recentemente, algumas empresas de perfuração constataram entradas de água em até $300 \mathrm{~m}$ de profundidade, e as vazões de explotação dos poços atingiram valores da ordem de $100 \mathrm{~m}^{3} \cdot \mathrm{h}^{-1}$.

\section{Utilização das águas do Sistema Aqüífero Serra Geral (SAG) para irrigação}

A classificação das águas do SASG para irrigação foi feita utilizando-se o diagrama que relaciona a razão de adsorção de sódio com a condutividade elétrica da água, proposto pelo U.S.Salinity Staff (1954).

As águas do SASG apresentam o Risco de
Sódio variando de Baixo a Médio e o Risco de Salinidade é predominantemente Baixo, sendo que apenas em alguns casos o Risco de Salinidade é Médio (figura 5).

Tendo em conta que o aqüífero é heterogêneo e anisotrópico, o volume de água passível de ser extraído, difere de local para local, sendo a capacidade de produção regulada pela recarga natural que por sua vez deve condicionar o regime diário de bombeamento, para uma explotação sustentável do recurso hídrico subterrâneo

Assim, torna-se imprescindível que a locação de poços seja feita buscando a existência de descontinuidades geológicas, bem como de estudos que estabeleçam o balanço hídrico, para determinação da recarga. Somente de posse desses dados torna-se possível estabelecer as vazões explotáveis por meio de poços em determinado mês do ano.

Para vazões de poços entre $25 \mathrm{~m}^{3} \cdot \mathrm{h}^{-1}$ e 100 $\mathrm{m}^{3} \cdot \mathrm{h}^{-1}$, a capacidade para irrigar uma determinada plantação de soja pode abranger uma área que varia entre $600.000 \mathrm{~m}^{2}$ e $2.400 .000 \mathrm{~m}^{2}$, respectivamente.

A utilização dessa água para irrigar a soja nos meses de estiagens deverá ser feita preferencialmente durante a noite devido à elevada insolação e perda da água do solo por evapotranspiração. 


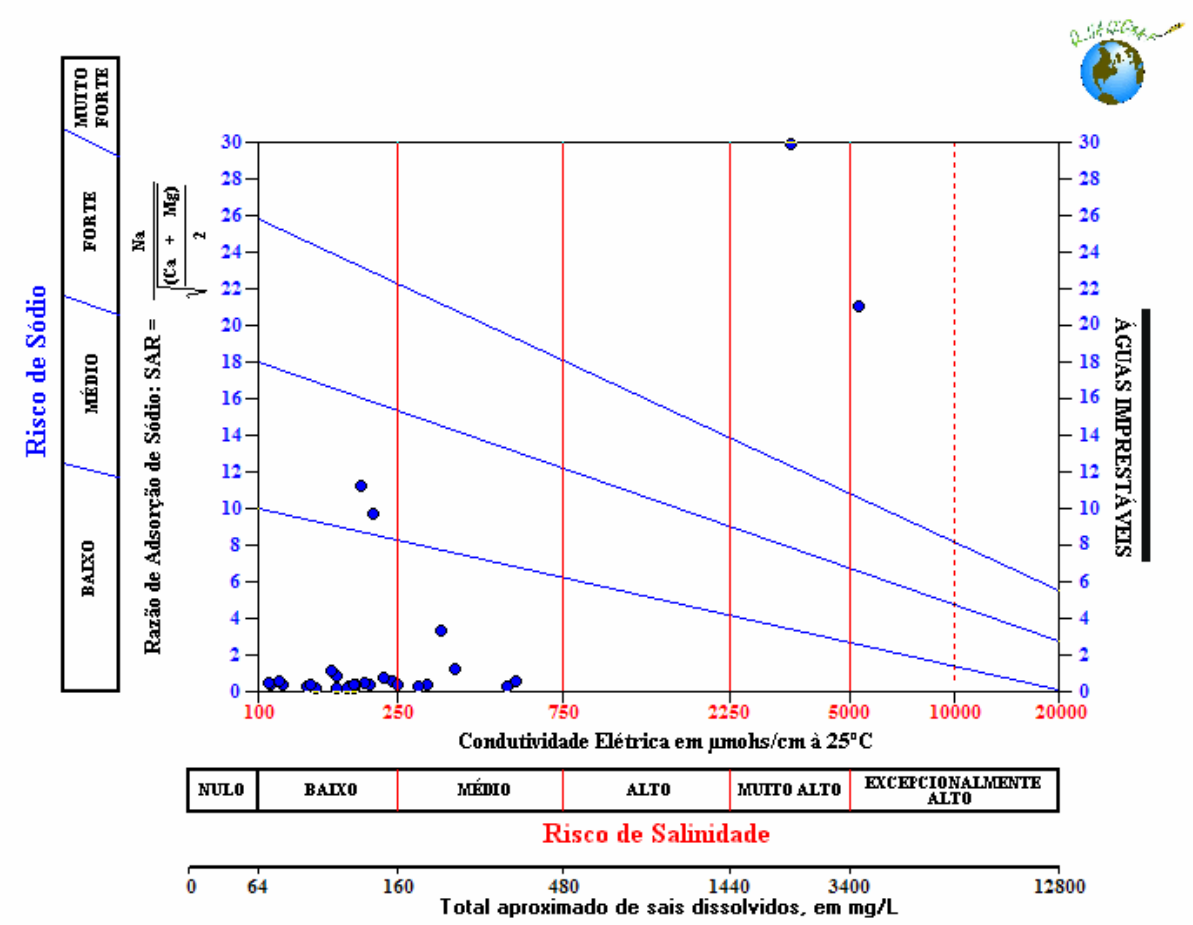

Figura 5- Diagrama de classificação de água para irrigação (U.S. Salinity Staff, 1954), com amostras de águas do SASG (HINDI, 2007)

Figura 5- Diagram for the classification of irrigation waters (U.S. Salinity Staff, 1954) showing water samples from Serra Geral Aquifer System (HINDI, 2007)

\section{CONCLUSÃO}

A colheita de grãos de soja e milho que são plantados nos meses de janeiro e fevereiro de cada ano, nas regiões do oeste e sudoeste do Paraná, não poderá estar totalmente garantida por conta da irregularidade das chuvas que já se manifestou de forma acentuada nos anos de 2004 e 2005. Uma alternativa para evitar este tipo de prejuízo que se irradia para toda economia paranaense e de certa forma brasileira, é representada pela captação das águas armazenadas no SASG.

Portanto, recomenda-se que simultaneamente à aquisição de semente da soja sejam inseridos como insumos os seguintes elementos: poço tubular profundo, tubulação apropriada à irrigação por aspersão e construção de reservatórios a serem implantados preferencialmente nos divisores de água das microbacias. 


\section{REFERÊNCIAS}

BITTENCOURT, A.V.L. Sólidos hidrotransportados na bacia hidrográfica do Rio Ivaí: Aplicação de balanços hidrogeoquímicos na compreensão da evolução de processos da dinâmica externa Tese de Doutorado, USP. 201p. 1978

CELliGOI, A. Aspectos hidrogeoquímicos da Formação Serra Geral em Londrina - PR. In: CONGRESSO BRASILEIRO. DE ÁGUAS SUBTERRÂNEAS., 8, Recife, 1994. Anais... Recife: ABAS. p.425-433

FERREIRA, F.J.F Alinhamentos estruturais magnéticos da região centro oriental da Bacia do Paraná e seu significado tectônico. Geologia da Bacia do Paraná. Reavaliação da potencialidade e prospectividade em hidrocarbonetos Paulipetro Consórcio CESP/IPT, São Paulo, 1982, p.143-166

HINDI, E.C. Hidrotermalismo e hidroquímica do Sistema Aquífero Guarani no Estado do Paraná Departamento de Geologia, Universidade Federal do Paraná. Tese de Doutorado. 180 p. Curitiba.

IAPAR - Instituto Agronômico do Paraná. Desvios da Precipitação Mensal. Disponível em: http://200.201.27.14/Site/Sma/Clima_2005/Clima_20 05.htm, acesso em junho/2007.

LEINZ, V. Contribuição à geologia dos derrames basálticos do sul do Brasil. Boletim da Faculdade de Filosofia, Ciências e Letras, São Paulo, Geol. 5, 1949. 103p.

MINEROPAR - Minerais do Paraná S.A. Mapa Geológico do Paraná do Estado do Paraná. Escala 1:650.000. MME-DNPM-MINEROPAR, 1989.

PICCIRILLO, E.M; COMINCHIARAMONTI, P; MELFI, A.J.; STOLFA, D.; BELLIENI, G.; MARQUES, L.S.; GIARETTA, A; NARDI, A.J.R.; PINESE, J.P.P.; RAPOSO, M.I.; ROISENBERG, A. Petrochemistry of continental flood basalt-rhyolite suites and related intrusives from the Paraná basin. In: PICCIRILLO, E.M.; MELFI A.J. (Org.). The Mesozoic Flood Volcanism of the Paraná Basin. São Paulo: IAG-USP, p.107-156, 1988.
PORTELLA FILHO C.V. 2002. Conexão hidráulica entre os Aquíferos Serra Geral e Guarani na região de Londrina - Maringá - PR com base em dados aeromagnetométricos e hidroquímicos Departamento de Geologia, Universidade Federal do Paraná, Dissertação de Mestrado. 128 p. Curitiba. REBOUÇAS, A.C. Potencialidades hidrogeológicas dos basaltos da Bacia do Paraná no Brasil. In: CONGRESSO BRASILEIRO DE GEOLOGIA, 30, Recife, 1978. Anais..., v.6, Recife: SBG. p.29631976

ROSA FILHO, E.F. da; SALAMUNI, R.; BITTENCOURT, A.V.L. Contribuição ao estudo das águas subterrâneas nos basaltos no Estado do Paraná. Boletim Paranaense de Geociências, n37, 1987. p.22-52

RÜEGG, N.A. Aspectos geoquímicos, mineralógicos e petrográficos de rochas basálticas da Bacia do Paraná, São Paulo, 1969. Tese (Doutorado), USP, 1969.

SOARES, P.C., MATTOS, J.T., BALIEIRO, M.G., BARCELLOS, P.R., MENEZES, P.R., GUERRA, S.M.S., CSORDAS, S.M. Imagens de Radar e Landsat na Bacia do Paraná. In: SIMPÓSIO SUL REGIONAL GEOLOGIA, 3, Curitiba, 1981. Anais... Curitiba: SBG.-NSP. p.201-216

STRUGALE, M. Arcabouço e Evolução estrutural do arco de Ponta Grossa no Grupo São Bento (Mesozóico): implicações na hidrodinâmica do Sistema Aqüífero Guarani e na migração de hidrocarbonetos na bacia do Paraná. 2002. 124p. Dissertação (Mestrado) - Departamento de Geologia, Universidade Federal do Paraná, Curitiba, 2002.

U.S. Salinity Staff. Dagnosis and improvement of saline and alkali soils. U.S. Department of Agriculture, Agriculture Handbook, n.60, 160p., Washington, DC, 1954.

VIEIRA, A.J. Geologia do centro e nordeste do Paraná e centro - sul de São Paulo. In: CONGRESSO BRASILEIRO DE GEOLOGIA, 27., 1973, São Paulo, Anais..., São Paulo: SBG, 1973. v.3, p.259 277. 